\title{
PENETRAÇÃO DE CLORETOS EM CONCRETO EM CÂMARA DE NÉVOA SALINA - ANÁLISE DO EFEITO DA CLASSE DE RESISTÊNCIA E DO TIPO DE REVESTIMENTO.
}

\author{
N. BRUGNERA ${ }^{1 *}$, F. PACHECO ${ }^{2}$, R. CHRIST $^{3,}$ H.Z. EHRENRING ${ }^{4}$ \\ *Autor de Contacto: eng.nataliab@gmail.com
}

\footnotetext{
${ }^{1}$ Engenheira Civil e Pós-Graduada em Desempenho e Patologia das Construções pela Universidade do Vale do Rio dos Sinos - UNISINOS

${ }^{2}$ Engenheira Civil e Doutora pela Universidade do Vale do Rio dos Sinos - UNISINOS, pesquisadora itt Performance

${ }^{3}$ Engenheiro Civil e Doutor pela Universidade do Vale do Rio dos Sinos - UNISINOS, pesquisador itt Performance

${ }^{4}$ Engenheiro Civil e Doutor pela Universidade do Vale do Rio dos Sinos - UNISINOS, pesquisador itt Performance
}

\section{RESUMO}

A agressividade provocada pelos íons cloreto no concreto é conhecida e difundida no meio científico. As normas técnicas traduzem através de requisitos de composição dos concretos como eles podem resistir a tais danos, de modo a apresentar durabilidade satisfatória. Avaliou-se através do ensaio acelerado de névoa salina, regido pela ASTM B117 dois diferentes concretos, contando ainda com os revestimentos epóxi e acetinado. A análise foi realizada através de aspersão do reagente químico de nitrato de prata nos corpos de prova e identificando assim a espessura da frente agredida pelos íons cloreto. Os resultados obtidos com a análise apontaram que os corpos de prova revestidos a base de epóxi são mais resistentes a penetração dos íons cloretos em relação ao revestimento acrílico, além disso estão diretamente relacionados ao menor valor de fator água/cimento.

Palavras chave: durabilidade do concreto, penetração de cloretos, ensaio acelerado.

\begin{abstract}
The aggressiveness caused by chloride ions in concrete is known and widespread in scientific circles. The technical standards translate through concrete composition requirements how they can withstand such damage, in order to present satisfactory durability. Two different concretes were evaluated through the accelerated salt spray test, governed by ASTM B117, with epoxy and satin coatings. The analysis was performed by spraying the chemical reagent of silver nitrate on the specimens and thus identifying the thickness of the front damaged by chloride ions. The results obtained from the analysis showed that the epoxy-based coated specimens are more resistant to the penetration of chloride ions in relation to the acrylic coating, in addition they are directly related to the lower value of water/cement factor.
\end{abstract}

Keywords: concrete durability, chloride penetration, accelerated test.

\section{INTRODUÇÃO}

O dimensionamento das estruturas de concreto armado foi pautado por muito tempo apenas em suas propriedades mecânicas. Atualmente, no entanto, sabe-se que a durabilidade é um parâmetro 
de projeto que deve ser levado em consideração (GJORV, 2014; NEVERKOVICA; KORJAKINS, 2014). Segundo Chemrouk (2015), os aspectos relacionados à durabilidade têm relação direta com a sustentabilidade das edificações.

$\mathrm{O}$ rápido aumento dos números de manifestações patológicas é uma forte indicação de que as edificações estão envelhecendo de forma precoce. Esse crescimento ocorre pelo emprego inadequado de práticas construtivas durante as etapas de planejamento, projeto, materiais, execução, manutenção e utilização além da combinação de efeitos do ambiente agressivo com os problemas relacionados a estrutura (ANDRADE, 2001). Na atualidade, percebe-se que países desenvolvidos já gastam mais com reparo e recuperação do que com novas edificações, e países em desenvolvimento ainda tem construções com deterioração precoce (CHEMROUK, 2015; HERBERT; LI, 2012)

Segundo Helene (2013), uma das manifestações mais frequentes nas estruturas de concreto é a corrosão de armaduras. A corrosão das armaduras é uma manifestação patológica que pode comprometer as propriedades mecânicas e a durabilidade dos elementos estruturais e de difícil solução. A corrosão pode ser desencadeada pelo fenômeno de carbonatação do concreto. Segundo Pack et al (2018), esse fenômeno ocorre quando o dióxido de carbono presente na atmosfera ingressa no concreto formando o carbonato de cálcio. Assim, reduz-se o ph do concreto, desestabilizando o filme de passivação que envolve as barras e causando sua agressão. Bagha, Yekefallah e Shayanfar (2020) pontuam que esse ataque depende dos fatores ambientais, da composição do concreto e das condições de operação das edificações.

Estratégias podem ser implementadas visando a redução da ocorrência do ataque salino em edificações. Em termos de estrutura de concreto, seu revestimento pode impactar e proporcionar proteção. Considerando esse cenário, este trabalho tem por objetivo avaliar a influência do tipo de revestimentos superficial no ingresso de cloretos. Para tanto corpos-de-prova com diferentes condições superficiais de revestimento foram submetidos a 4.500 horas em uma câmara de névoa salina e posteriormente a penetração dos íons cloretos foi determinada através da aspersão de nitrato de prata.

\section{PROCEDIMENTO}

A medição do avanço da frente de íons cloretos, foi realizada através da aspersão de solução de nitrato de prata, posterior a retirada das amostras da câmara de névoa salina, que permaneceram por 4.500 horas. No total foram moldadas 18 amostras, 9 com concreto de traço TR1 e as demais com traço TR2. Desse total, 3 corpos de prova de cada traço ficaram sem revestimento para serem utilizadas como referência. Em cada traço, 3 corpos de prova foram revestidos com tinta epóxi e outros 3 com tinta acetinada. Na Figura 1 observa-se, através do fluxograma, as etapas que compreenderam a realização do programa experimental. 


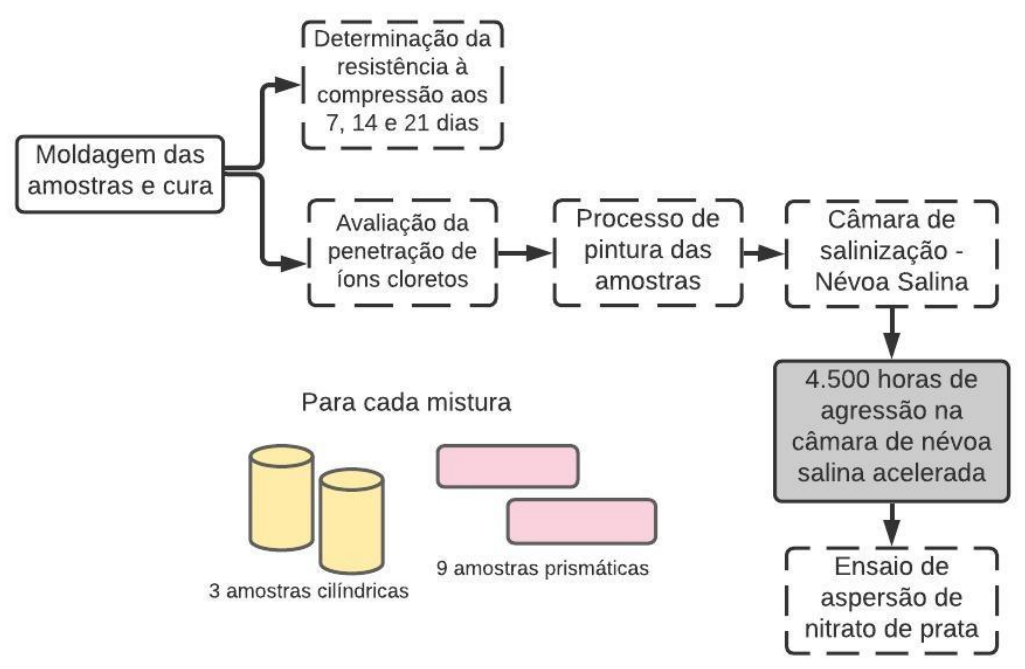

Figura 1 - Fluxograma das etapas do programa experimental.

\subsection{Confecção das amostras}

Como demonstrado na Figura 1, para cada traço foram desenvolvidas amostras cilíndricas e prismáticas e colocadas em ambiente de agressão acelerada. Cada mistura contou com dois tipos de revestimentos, sendo tinta epóxi e tinta acetinada. Foram guardadas duas amostras sem pintura. As amostras confeccionadas têm formato cilíndrico, de diâmetro $100 \mathrm{~mm}$ de altura de $200 \mathrm{~mm}$, moldadas conforme a NBR 5738 (ABNT, 2015) para o ensaio de resistência mecânica à compressão. As amostras expostas à câmara de névoa salina, para análise da penetração de íons cloretos, utilizou-se amostras prismáticas, com dimensões de $60 \mathrm{~mm}$ x $60 \mathrm{~mm}$ e comprimento de $180 \mathrm{~mm}$. As fôrmas para as amostras cilíndricas utilizadas foram metálicas e as amostras prismáticas de madeira, além disso, utilizou-se desmoldante em ambas. A desforma de todas as amostras ocorreu 24 horas após a moldagem.

A cura foi conduzida em câmara de umidade controlada. Para a caracterização mecânica dos traços, foi avaliada sua resistência à compressão através das amostras cilíndricas, sendo as idades de análise 7, 14 e 28 dias, contando sempre com duas amostras.

\subsection{Câmara de névoa salina}

$\mathrm{O}$ ataque por íons cloreto ocorreu através de exposição das amostras em ambiente de ensaio preconizado na ASTM B117:2011. A câmara de ensaio empregou uma concentração de cloreto de sódio $(\mathrm{NaCl})$ de $5 \%$, com o ambiente saturado, temperatura interna de $35^{\circ} \mathrm{C}$ e $\mathrm{Ph}$ da solução salina entre 6,5 e 7,2. As amostras permaneceram na câmara por 4.500 horas. A Figura 2 apresenta a câmara utilizada para o ensaio. 


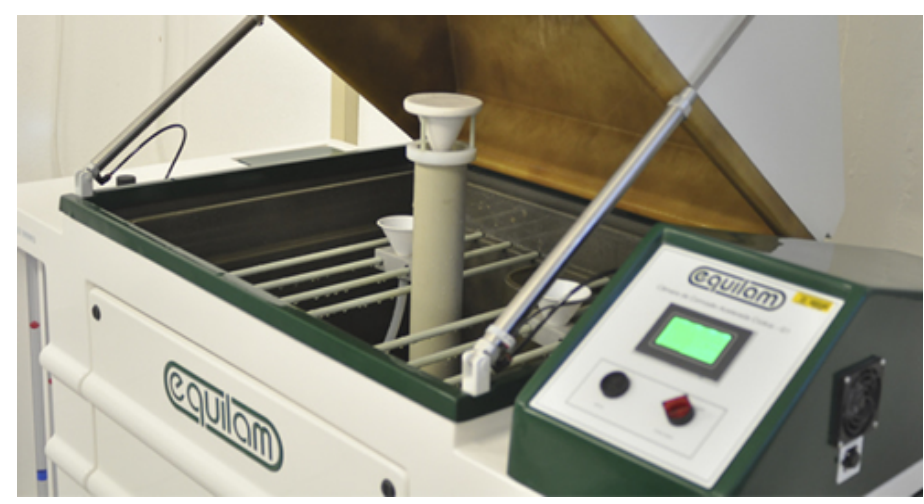

Figura 2- Câmara de névoa salina. Fonte: Site ITT Fuse.

\subsection{Materiais utilizados}

Os traços utilizados em massa e o fator água/cimento estão apresentados na Tabela 1.

Tabela 1 - Composição dos traços.

\begin{tabular}{|c|c|c|}
\cline { 2 - 3 } \multicolumn{1}{c|}{} & TR1 & TR2 \\
\hline cimento:areia:brita & $1: 2,77: 3,43$ & $1: 2,14: 3,05$ \\
\hline fator água/cimento & 0,49 & 0,46 \\
\hline
\end{tabular}

O concreto foi disponibilizado por uma concreteira situada na cidade de Passo Fundo/RS.

\subsubsection{Aditivo superplastificante}

Utilizou-se aditivo superplastificante, o uso do aditivo foi de $0,15 \%$ em relação à massa de cimento do traço TR 1 e $0,38 \%$ em relação à massa de cimento do TR2. A densidade do superplastificante a $20^{\circ} \mathrm{C}$ é 1,05 a $1,07 \mathrm{~g} / \mathrm{cm}^{3}$ e apresenta teor de cloretos menor que $0,1 \%$, informações oriundas do fabricante.

\subsubsection{Materiais de revestimento}

Para as duas tintas foram utilizadas duas demãos.

\section{a) Tinta Epóxi}

Utilizou-se tinta epóxi, com acabamento epóxi poliamida, bi componente, de baixa espessura, este produto atende a norma Petrobras N 1198 Tipo II. As características são: aspecto brilhante, com espessura de 30 micrometros seco, com rendimento de $14 \mathrm{~m}^{2} /$ litro, temperatura máxima de $90^{\circ} \mathrm{C}$.

\section{b) Tinta Acetinada}

A tinta acetinada é uma emulsão acrílica, composta por espessantes, pigmentos, cargas minerais, aditivos, dispersantes, conservantes e água. As características da tinta são viscosidade de 100$105 \mathrm{KU}$, densidade de $1,37 \mathrm{~g} / \mathrm{cm}^{3}$ e ph variando de 8 a 9,5 .

\section{PROCEDIMENTO EXPERIMENTAL}

\subsection{Ensaio de resistência à compressão}

O ensaio de resistência mecânica à compressão foi realizado nas idades de 7, 14 e 28 dias, sempre contando com três amostras por traço, conforme as diretrizes da ABNT NBR 7680 (2015). 


\subsection{Determinação do ataque por cloretos}

Com a utilização de aspersão do indicador químico de solução de nitrato de prata (AgNO3), foi realizada a verificação da frente de ataque por cloretos nos corpos de prova. De modo que fosse verificado a diferença da resistência ao ataque por cloretos dos revestimentos, seis corpos de prova foram selados com o uso de tinta à base de epóxi, seis com tinta acetinada a base de água, ambas aplicadas em duas demãos nas amostras e outras oito sem revestimento.

Após permanecerem na câmara salt spray os corpos de prova foram submetidos a aspersão com uma solução de nitrato de prata. Foram avaliados dois tipos de revestimento de superfície e dois traços de concreto.

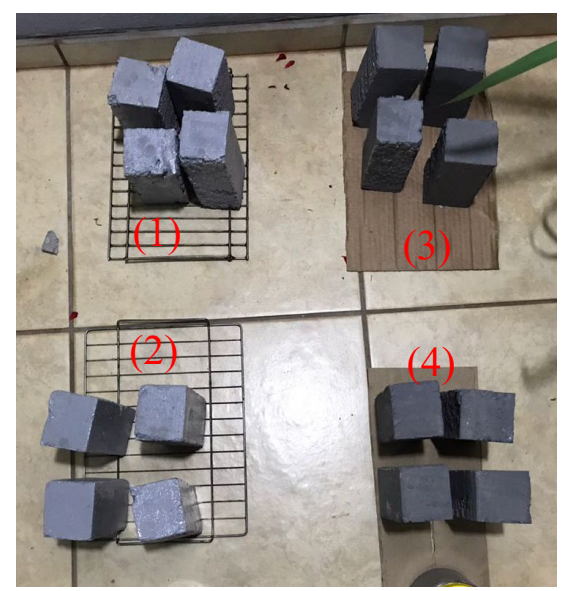

Figura 3 - Corpos de prova 1 e 2 após aplicação de tinta epóxi e 3 e 4 após a aplicação de tinta acetinada.

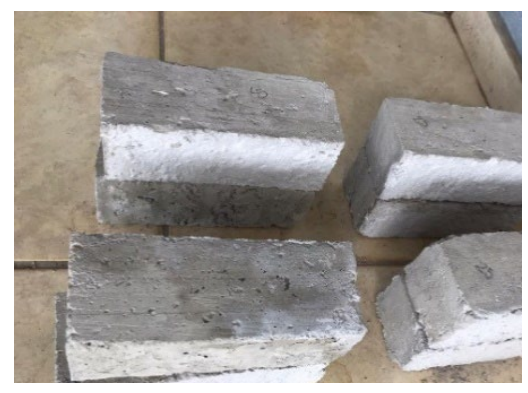

Figura 4 - Corpos de prova sem a aplicação de revestimentos.

A solução química de nitrato de prata possui coloração marrom para áreas onde não há presença de cloretos e mantém a identificação natural do concreto para áreas atacadas. Entretanto, a coloração da solução química de nitrato de prata não possui tamanha nitidez nas amostras de concreto, sendo difícil identificar as zonas agredidas e ilesas.

Por esse motivo, com o uso do software Arc Map 10.3, identificou-se diferentes pontos de coloração da imagem e permitindo realizar a identificação das áreas com maior penetração de cloretos, conforme observa-se na Figura 5. 


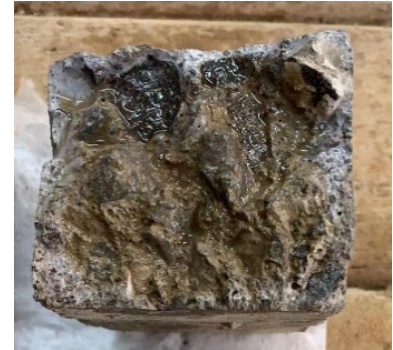

(1)

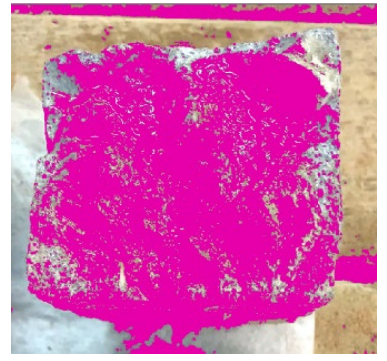

(2)

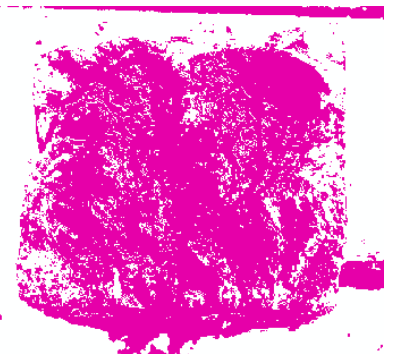

(3)

Figura 5 - Fotografias 1 e 2 das amostras com identificação de tonalidade e imagem 3 gerada após identificação de tonalidade.

Após o tratamento das imagens, procedeu-se com a mensuração das frentes de penetração dos íons cloreto pelo uso do AutoCadTM.

Nas imagens da Figura 5, está apresentado uma amostra do TR1 sem revestimento.

\section{RESULTADOS}

\subsection{Característica mecánica dos traços}

O ensaio de resistência mecânica à compressão foi realizado nas idades de 7, 14 e 28 dias, sempre contando com uma amostra por idade. Os resultados obtidos são apresentados na Tabela 2.

Tabela 2 - Resultados na determinação da resistência à compressão.

\begin{tabular}{|c|c|c|c|c|}
\hline \multirow{2}{*}{ Traço } & No CP & $\begin{array}{c}\text { Carga de } \\
\text { Ruptura } \\
(\mathrm{kgf})\end{array}$ & $\begin{array}{c}\text { Área } \\
\left(\mathrm{mm}^{2}\right)\end{array}$ & $\begin{array}{c}\text { Resistência à } \\
\text { compressão } \\
(\mathrm{MPa})\end{array}$ \\
\hline \multirow{3}{*}{ TR1 } & 1 & 11214 & 7854,0 & 14,0 \\
\cline { 2 - 5 } & 2 & 14661 & 7854,0 & 18,3 \\
\cline { 2 - 5 } & 3 & 14938 & 7697,7 & 19,0 \\
\hline \multirow{3}{*}{ TR2 } & 4 & 12426 & 7697,7 & 15,8 \\
\cline { 2 - 5 } & 5 & 13439 & 7854,0 & 16,8 \\
\cline { 2 - 5 } & 6 & 14223 & 8011,8 & 17,4 \\
\hline
\end{tabular}

A Figura 6, apresenta os valores obtidos no ensaio de resistência a compressão.

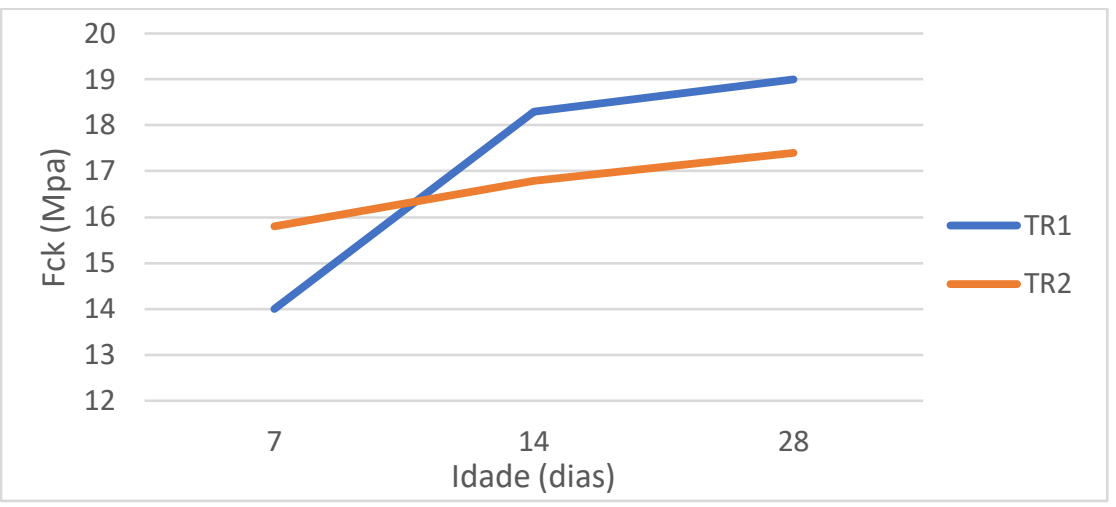

Figura 6 - Valores obtidos de resistência à compressão.

Conforme apresentado na Figura 6, não houve um comportamento similar entre os dois traços. O traço 1 apresentou evolução de resistência à compressão com o valor final de somente 3,68\% superior a verificação aos 14 dias, tendo apresentado o maior valor nas idades de 14 e 28 dias. $\mathrm{O}$ 
traço 2 apresentou resistência à compressão sempre em ascendência, com apenas 3,45\% superior a idade de 14 dias para 28 dias. Avalia-se que as composições do concreto apresentadas não têm comportamento final em concordância com o estipulado em norma, além de não atingirem a resistência à compressão especificada pela fornecedora de concreto. Dessa forma, observou-se um crescimento da resistência com a idade, bem como a influência da relação água/cimento na resistência à compressão.

Conforme citado, podem ser atribuídas a estas amostras falhas no experimento, podendo ser advindas da falta de linearidade dos corpos de prova, da existência de vazio em seu interior, teor de umidade no momento do ensaio, entre outros. De acordo com Mehta e Monteiro (2014), concretos com maior resistência à compressão apresentam valores menores de índice de vazios, sendo a presença de vazios uma desvantagem para o ganho de resistência e o suporte de carga dos concretos.

Inúmeros estudos já desenvolvidos relatam esta relação entre o índice de vazios do concreto e sua resistência à compressão, como o de Shinde e Valunkjar (2015) que, ao desenvolverem concretos permeáveis, e portanto com elevado índice de vazios, perceberam a redução da resistência à compressão; e o de Campos, Mazini e Neto (2012), que, ao incorporarem agregado de maior índice de vazios causaram este acréscimo nos vazios totais do concreto e reduziram linearmente a resistência à compressão das composições.

\subsection{Frente de ataque por cloretos}

A verificação da frente de ataque por cloretos foi realizada em 4.500 horas após a colocação das amostras na câmara de salt spray. Os valores estão apresentados na Tabela 3. Os resultados da penetração estão apresentados em milímetros e foram determinados em comparação com os três diferentes revestimentos.

Tabela 3 - Valores máximos de frente de penetração de névoa salina.

\begin{tabular}{|c|c|c|c|}
\hline $\begin{array}{c}\text { Identificação das } \\
\text { amostras }\end{array}$ & Sem revestimento & Revestimento Epóxi & $\begin{array}{c}\text { Revestimento } \\
\text { Acetinado }\end{array}$ \\
\hline \multicolumn{4}{|c|}{ Traço - TR1 } \\
\hline Amostra 1 & 21,5 & 8 & 12,8 \\
\hline Amostra 2 & 14,6 & 3,6 & 9,9 \\
\hline Amostra 3 & 18,3 & 2,5 & 12,3 \\
\hline \multicolumn{4}{|c|}{ Traço - TR2 } \\
\hline Amostra 1 & 15,8 & 2,1 & 5,4 \\
\hline Amostra 2 & 13,2 & 3,6 & 7,7 \\
\hline Amostra 3 & 18,5 & 2,1 & 10,3 \\
\hline
\end{tabular}

A Figura 7 ilustra o comportamento obtido frente a penetração de cloretos para o traço TR1 e TR2. 


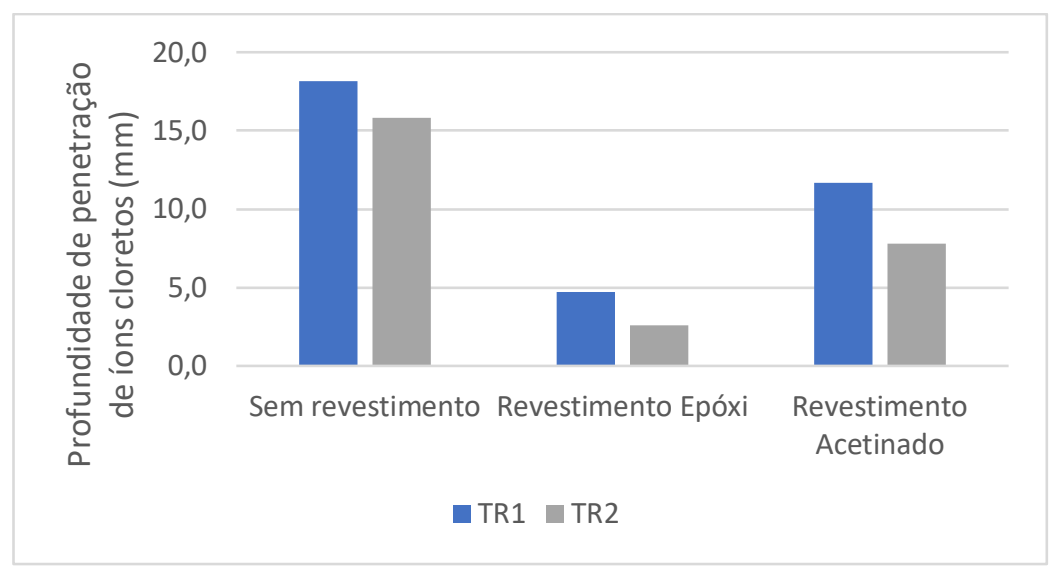

Figura 7 - Resultados dos valores máximos obtidos de frente de penetração dos íons cloretos no concreto de TR1 e TR2.

No gráfico da Figura 7, observa-se a influência do tipo de revestimento superficial utilizado, na penetração dos íons cloretos após 4.500 horas submetidos a câmara salt spray.

Verifica-se que foram obtidas diferenças consideráveis de penetração dos íons cloretos entre os revestimentos utilizados em comparação com as amostras sem revestimento. Sabe-se que os valores retirados na medição dos corpos de prova foram os máximos valores obtidos de frente de íons cloretos e no gráfico está apresentado a média entre eles. Os valores maiores de penetração foram apresentados pelos corpos de prova sem revestimento, chegando a $18,1 \mathrm{~mm}$ no TR1 e 15,8 $\mathrm{mm}$ no TR2. Já nas amostras com revestimento acetinado, os valores de ingresso de cloretos reduziram chegando ao valor máximo de $11,7 \mathrm{~mm}$. Nos corpos de prova revestidos com tinta à base de epóxi, os valores de penetração de cloretos diminuíram significativamente, com no máximo $4,7 \mathrm{~mm}$.

As verificações de frente de ataque por cloretos no concreto de traço TR2, resultaram em valores menores do TR1, quando comparados os mesmos tipos de revestimento. Este resultado indica a influência da relação água/cimento no comportamento de concretos frente à penetração de cloretos. Isso se confirma nos estudos de Teixeira e Costa (2020) e Oliveira et al (2020), consequentemente, em que mostra a penetração de íons cloretos em média até $25,15 \mathrm{~mm}$ com fator água/cimento de 0,60 e 12,75 mm de penetração de íons cloretos e fator água/cimento de 0,45 .

Ainda no gráfico 7, pode-se observar os resultados obtidos nos corpos de prova sem revestimento. Conforme observa-se, os valores obtidos de ataque de cloretos do traço TR1 foram menores do que a penetração no traço TR2. Em relação aos resultados com revestimento, os corpos de prova com tinta epóxi demonstram ser mais resistentes ao ataque de íons cloretos.

Nos corpos de prova com revestimento acetinado, foram encontrados valores de penetração de íons cloretos consideráveis, comparados com as amostras sem revestimentos.

\section{CONCLUSÃO}

O estudo consistiu na moldagem de corpos de prova cilíndricos e prismáticos. Os cilíndricos foram testados a resistência à compressão e os corpos de prova prismáticos foram revestidos com tintas epóxi e acetinada, após foram levados à câmara de névoa salina, que permaneceram por 4.500 horas. Com a utilização de aspersão da solução de nitrato de prata, foi feita a medição da frente de penetração de íons cloretos nos corpos de prova.

Os resultados obtidos com a medição do ataque dos íons cloretos nas amostras utilizando diferentes tintas referenciadas pelo concreto sem revestimento, explicitaram a importância em proteger estruturas de concreto, pois contribui para a longevidade e durabilidade. 
Com o estudo, foi possível analisar a influência das propriedades que compõem o concreto. Com a medição da frente de penetração dos íons cloretos nas amostras verificou-se que além da utilização das proteções do concreto com tintas, a diferença na composição dos traços implica na durabilidade.

No concreto de traço TR1, utilizou-se um fator água/cimento de 0,46 , que torna o concreto com porosidade baixa e consequentemente mais resistente aos agentes agressivos, neste caso os íons cloretos. Já no TR2, a porosidade gerada foi maior, devido a quantidade de água (fator água/cimento igual a 0,49 ) em relação a quantidade de cimento utilizada.

Dessa forma, conclui-se que os resultados são função exclusivamente do fator água/cimento, pois comanda a porosidade e consequentemente a facilidade dos íons cloretos penetrarem.

\section{REFERÊNCIAS}

Associação Brasileira de Normas Técnicas. NBR 15575-1: Edificações habitacionais Desempenho Parte 1: Requisitos gerais. Rio de Janeiro.

. NBR 6118: Projeto de estruturas de concreto - Procedimento. Rio de Janeiro: Associação Brasileira de Normas Técnicas, 2014. 238 p.

. NBR 7680: Concreto - Extração, preparo, ensaio e análise de testemunhos de estruturas de concreto. Rio de Janeiro: Associação Brasileira de Normas Técnicas, 2015. 27 p.

. NBR 5738: Concreto - Procedimento para moldagem e cura de corpos de prova. Rio de Janeiro: Associação Brasileira de Normas Técnicas, 2015. 9 p.

. NBR NM 248: Agregados - Determinação da composição granulométrica. Rio de Janeiro: Associação Brasileira de Normas Técnicas, 2003. 6 p.

. NBR NM 45: Agregados - Determinação da massa unitária e do volume de vazios. Rio de Janeiro: Associação Brasileira de Normas Técnicas, 2006. 8 p.

. NBR NM 46: Agregados - Determinação do material fino que passa através da peneira 75 um, por lavagem. Rio de Janeiro: Associação Brasileira de Normas Técnicas, 2011. 6 p.

American Society for Testing and Materials. ASTM B 117: Standard Practice for Operating Salt Spray (Fog) Apparatus. West Conshohocken.

Andrade, J. J. O. (2001), Contribuição à previsão da vida útil das estruturas de concreto armado atacadas pela corrosão de armaduras: iniciação por cloretos. Dissertação (Doutorado). Universidade Federal do Rio Grade do Sul, Porto Alegre.

BAGHA, M.G; YEKEFALLAH, M.R; SHAYANFAR, M.A. Durability of RC Structures agains carbonation-induced corrosión under the impact of climate change. KSCE Journal of Civil Engineering, 24, 131-142, 2020.

Campos, C. F. S.; Mazzini, G. B,; Silva Neto, G. A. Análise das propriedades físicas e mecânicas do concreto produzido com resíduo sólido de cerâmica vermelha. Colloquium Exactarum. v. 4, n.2, 2012. p. 01-11. 
CELADYN, W. Innovative Structural Systems. v. 1, n. International Scientific Workshops „Innovative Structural Systems in Architecture” (ISSA2016) November 3-5, 2016, Wrocław, Poland, 2016.

CHEMROUK, M. The deteriorations of reinforced concrete and the option of high performances reinforced concrete. In: The 5th international conference of Euro Asia Civil Engineering ForumEACEF 5. Procedia Engineering 125, p 713-724, 2015.

CZARNECKI, L; GERYLO, R; KUCZYNSKI, K. Concrete repair durability. Materials, 2020 , 13, 4535.

GJØRV, Odd E. Durability Design of Concrete Structures in Severe Environments. 2. ed. Boca Raton: Crc Press, 2014

HELENE, Paulo. Os Principais Mecanismos de Deterioração que Prejudicam a Vida Útil da Estrutura. Gramado: $55^{\circ}$ Congresso Brasileiro do Concreto, 2013. Color.

HERBERT, E.; LI, V. Self-healing of engineered cementitious composites in the 351 natural environment. Performance Fiber Reinforced Cement Composites 6, p. 155-162, 2012.

KIM, M. J.; ANN, K. Y. Corrosion Risk of Reinforced Concrete Structure Arising from Internal and External Chloride. Advances in Materials Science and Engineering, v. 2018, 2018.

MEHTA, P. K. Durability of Concrete - Fifty Years of Progress? In: Seminário Qualidade e Durabilidade das Estruturas de Concreto. (Anexo aos Anais). Porto Alegre, NORIE/CPGEC/UFRGS, 1993. 33 p.

MEHTA, P. Kumar; MONTEIRO, Paulo J. M. Concreto: Microestrutura, Propriedades e Materiais. 2. ed. São Paulo: IBRACON, 2014. 782 p.

NEVERKOVICA, D.; KORJAKINS, A. Influence of Additives on Reinforced Concrete Durability. Construction Science, v. 16, n. 1, p. 21-26, 2014.

NEVILLE, Adam M. Propriedades do Concreto. 5. ed. Porto Alegre: Bookman, 2015. 912 p.

OLIVEIRA, G. Y. S.; FERREIRA, B. E. S.; GUEDES, J. F.; BARBOSA, E. S. Análise de Ataque por Cloretos em Concreto Leve Estrutural com Argila Expandida. Anais do Congresso Brasileiro da Patologia das Construções. Anais...2020

PACK, S; JUNG, M.S; KANG, J.W; ANN, K.Y; KIM, J. Assessment of Durability of Concrete Structure Subject to Carbonation with Application of Safety Factor. Advances in Materials Science and Engineering, vol. 2018.

RINCÓN, O.T et al. Reinforced Concrete Durability in Marine Environments DURACON Project: Long-Term Exposure. CORROSION 1 June 2016; 72 (6): 824-833.

RISSARDI, C. Z. ; DE SOUZA, C. F. N. ; PACHECO, F. ; CHRIST, R. ; SILVEIRA, L. F. . Chloride attack evaluation on concrete compositions according to Brazilian standard ABNT NBR 6118 specification. Journal of Building Pathology and Rehabilitation, v. 1, p. 19, 2016. 
SEUNG- WOO, P; JUNG, M.S; KANG, J.W; ANN, K.Y; KIM, J. Assessment of Durability of Concrete Structure Subject to Carbonation with Application of Safety Factor. Advances in Materials Science and Engineering, vol. 2018, Article ID 2430630, 10 pages, 2018.

SHAIKH, F. U. A. Effect of Cracking on Corrosion of Steel in Concrete. International Journal of Concrete Structures and Materials, v. 12, n. 1, 2018.

SHINDE, Gaurav Uttam; VALUNJKAR, S. S. An Experimental Study on Compressive Strength, Void Ratio and Infiltration Rate of Pervious Concrete. International Journal of Engineering Research and Technology, v. 4, n. 4, 2015.

SOUZA, Darcio Oliveira de et al. Investigação da corrosividade do ensaio de névoa salina segundo norma ISO 9227. In: Encontro e exposição brasileira de tratamento de superficie/III interfinish, 2012, São Paulo. Anais do EBRATS 2012. São Paulo: ABRATS, 2012. p. 360 - 367.

TANG, W.; KARDANI, O.; CUI, H. Robust evaluation of self-healing efficiency in cementitious materials - A review. Construction and Building Materials, v. 81, p. 233-247, 2015.

TEIXEIRA, F. R.; COSTA, V. S. Penetração de Cloretos em Concretos com Substituição Parcial do Aglomerante Pelo Resíduo do Beneficiamento de Rochas Ornamentais. Anais do Congresso Brasileiro da Patologia das Construções. Anais...2020 